\title{
Sustentabilidade na suinocultura de terminação: indicadores ambientais de desempenho em um município gaúcho
}

\author{
Sustainability in swine termination: environmental performance indicators in a \\ gaúcho county
}

\author{
Gabriela Allegretti ${ }^{* 1}$, Verônica Schmidt ${ }^{2}$ e João Armando Dessimon Machado ${ }^{3}$ \\ ${ }^{1}$ Doutoranda em Agronegócios, Universidade Federal do Rio Grande do Sul, Porto Alegre, Brasil. \\ ${ }^{2,3}$ CEPAN, Universidade Federal do Rio Grande do Sul, Porto Alegre, Brasil.
}

\begin{abstract}
Resumo
O incremento na participação da suinocultura brasileira no mercado mundial, nos últimos anos, associado às exigências impostas por estes novos mercados consumidores despertam para a necessidade de diagnósticos e análises direcionadas quanto à sustentabilidade do setor. Tendo por foco a dimensão ambiental da tríade de sustentabilidade proposta pelo Tripple Bottom Line (TBL), por meio do Método de Avaliação de Indicadores de Sustentabilidade (M.A.I.S.) organizacional adaptado à suinocultura de terminação, a pesquisa objetivou construir indicadores de desempenho ambiental voltados à sustentabilidade e a validação desta ferramenta no município de Aratiba-RS, detentor do maior rebanho suíno do estado do Rio Grande do Sul, no ano de 2011. Caracterizaram-se 10 indicadores de sustentabilidade ambiental bem como os índices para os níveis de equilíbrio, em busca de equilíbrio e em desequilíbrio. Determinou-se que os indicadores manejo de dejetos, licenciamento, descarte de resíduos sólidos e análise de solo, apresentaram-se como os mais críticos, uma vez que situaram-se próximos à faixa de desequilíbrio. Já os indicadores vetores e roedores, limpeza das instalações e bem estar animal apresentaram-se próximos à faixa de equilíbrio. Apesar das limitações verificadas nesta metodologia, quando confrontada à realidade das propriedades suinícolas avaliadas, esta ferramenta possibilitou a identificação dos pontos críticos avaliados na dimensão ambiental permitindo nortear ações privadas ou políticas públicas que visem o desenvolvimento sustentável do setor no município.
\end{abstract}

Palavras-chave: Indicadores ambientais, integração, desenvolvimento.

\begin{abstract}
The increased participation in recent years of Brazilian pig on the world market associated with the requirements imposed by these new consumer markets awake to the necessity of diagnostics and targeted analysis on sector's sustainability. Focusing on the environmental dimension of sustainability triad proposed by Tripple Bottom Line (TBL) through Método de Avaliação de Indicadores de Sustentabilidade organizacional (M.A.I.S.) adapted to swine termination, the research aimed to build environmental performance indicators focused on sustainability and validation of this tool in the city of Aratiba - RS, the largest producer of pigs in Rio Grande do Sul, in 2011. It was characterized 10 environmental sustainability indicators and indices for the levels of balance, for balance and imbalance. It was determined that the waste management, licensing, disposal of solid waste and soil analysis indicators are presented as the most critical as it stood near range imbalance. The indicators vectors and rodents, cleanliness of facilities and animal welfare were presented near equilibrium range. Despite the limitations noted in this methodology when confronted with the reality of pig assessed properties, this tool enabled the identification of critical points assessed in the environmental dimension guide allowing private actions and public policies aimed at sustainable development of the sector in the county.
\end{abstract}

Keywords: Environmental indicators, integration, development. 


\section{Introdução}

$\mathrm{O}$ s crescentes números da suinocultura brasileira nos mercados nacional e internacional, em função de incrementos em eficiência produtiva e competitividade do setor, alertam para a necessidade de avaliações e análises referentes à sustentabilidade da atividade.

O aumento da produção de carne suína no Brasil, nas últimas décadas, deu-se em função do aumento da escala, da especialização e da concentração geográfica da produção primária, concomitante ao aumento na participação dos contratos que regem as relações entre produtores e agroindústria (MIELE, 2006) envolvendo a maioria dos produtores na etapa de terminação.

O Brasil é considerado hoje o quarto produtor, o quarto exportador e quinto consumidor de carne suína mundial (RODIGHERI, 2011), tendo na região Sul 69,38\% da totalidade de produção do país com sistema federal de inspeção (SANTOS FILHO et al., 2011). O estado do Rio Grande do Sul representa 25,74\% destes números, e, através da propriedade familiar, atua nas diversas etapas de especialização da produção por meio das unidades produtoras de leitões (UPL), crechários (presente em alguns sistemas) e unidades de terminação (UT).

Na região Sul, estima-se que $92 \%$ dos estabelecimentos suinícolas tecnificados sejam integrados através de contratos ou programas de fomento pecuário das empresas e cooperativas agroindustriais (MIELE, 2006). Este sistema integrado de produção viabilizou financiamentos aos produtores, conferiu escala de comercialização às agroindústrias, facilitou a transferência de tecnologias, dentre outros benefícios para a cadeia produtiva da suinocultura permitindo, assim, o desenvolvimento de regiões como o Alto Uruguai gaúcho e catarinense e, mais recentemente, por meio do deslocamento destas indústrias para novos centros produtores de grãos, o desenvolvimento da atividade no centro-oeste brasileiro.

A intensificação da suinocultura nas últimas décadas promovida por este novo arranjo de governança, aliada às instabilidades no mercado de grãos que representaram, em 2010 por meio da alimentação, 67\% dos custos totais de produção da suinocultura de terminação em Santa Catarina (MIELE et al., 2011), provocaram mudanças no perfil de municípios e regiões suinícolas trazendo, consigo, consequências ambientais, sociais e econômicas a serem melhor avaliadas.

Cada vez mais reflexos ambientais estão sendo sentidos em função do alto potencial poluidor da atividade suinícola devidos aos dejetos gerados, atuando como pontos a serem observados na análise do desenvolvimento do setor, principalmente nas mais representativas regiões produtoras de suínos do estado, como é o caso da região considerada no presente estudo - o Alto Uruguai gaúcho, mais especificamente o município de Aratiba (RS).

Uma análise do ponto de vista ambiental torna-se fundamental para o reconhecimento e a confrontação dos pontos críticos hoje verificados, principalmente no que tange ao tema tratamento e destinação de dejetos possibilitando, assim, nortear as tomadas de decisões dentro do setor, a fim de se buscarem soluções mitigadoras destes impactos ambientais verificados com esta atividade.

A construção de indicadores específicos para cada atividade vem sendo o desafio de grande parte da pesquisa científica a fim de monitorar e avaliar o desempenho de diferentes setores. Segundo Claro e Claro (2004), na literatura sobre indicadores de sustentabilidade uma das lacunas identificadas diz respeito aos usuários destes indicadores, alertando que praticamente nenhum programa desenvolvido nas diferentes partes do mundo, diz respeito à aplicação imediata por parte dos produtores rurais, sendo os principais usuários sempre os elaboradores de políticas públicas e pesquisadores.

O presente estudo tem como uma de suas finalidades a construção de indicadores de desempenho na dimensão ambiental, voltados à sustentabilidade, que possam ser utilizados como forma de diagnosticar e comparar semelhantes dentro da atividade de suinocultura de terminação. Da mesma forma, a aplicação desta metodologia permite análises evolutivas da atividade em um dado município, estimulando e alertando tanto produtores como o poder público para os pontos críticos apresentados, norteando, assim, ações ou planejamentos estratégicos, tanto públicos como privados, voltados à busca do desenvolvimento sustentável do setor.

Concomitantemente, visando validar a ferramenta desenvolvida realizou-se a pesquisa no município de Aratiba considerado, no ano de 2011, o município detentor do maior rebanho suíno do Estado do Rio Grande do Sul (IBGE, 2011) formado, majoritariamente $(97,80 \%)$, por produtores de suínos em terminação organizados em sistemas integrados de produção (SEAPA/SAN, 2011) que possuem na atividade uma de suas principais formas de remuneração.

\section{Materiais e métodos}

A pesquisa ocorreu em duas etapas: construção de indicadores e adaptação da metodologia à suinocultura de terminação, e validação no município supracitado.

Primeiramente foi realizada pesquisa bibliográfica sobre a produção de suínos de terminação, focando nos aspectos ambientais. Posteriormente, realizaramse questionários abertos, na forma de entrevistas, com experts do setor e líderes da atividade.

A partir das informações coletadas durante as entrevistas, da confrontação com dados técnicos e científicos obtidos através das revisões bibliográficas construíram-se os indicadores de desempenho para a dimensão ambiental os quais foram organizados para aplicação na metodologia M.A.I.S. - Método de Avaliação de Indicadores 
Tabela 1: Indicadores para avaliação de desempenho ambiental na suinocultura de terminação em sistema integrado de produção

\begin{tabular}{|c|c|c|c|c|}
\hline \multirow[b]{2}{*}{$\begin{array}{l}\text { Indicadores } \\
\text { Ambientais }\end{array}$} & \multirow[b]{2}{*}{ Critério avaliado } & \multicolumn{3}{|c|}{ Critério para classificação } \\
\hline & & $\begin{array}{c}\text { Em } \\
\text { desequilíbrio } \\
(\text { valor } 1)\end{array}$ & $\begin{array}{l}\text { Em busca de } \\
\text { equilibrio } \\
\text { (valor 2) }\end{array}$ & $\begin{array}{l}\text { Em } \\
\text { equilíbrio } \\
\text { (valor 3) }\end{array}$ \\
\hline Licenciamento & $\begin{array}{l}\text { Possui e em que } \\
\text { fase se encontra }\end{array}$ & $\begin{array}{c}\text { Não possui } \\
\text { nem protocolo } \\
\text { FEPAM }\end{array}$ & $\begin{array}{l}\text { Somente } \\
\text { protocolo }\end{array}$ & Possui L.O. \\
\hline $\begin{array}{c}\text { Tratamento de } \\
\text { dejetos }\end{array}$ & $\begin{array}{l}\text { № esterqueiras e } \\
\text { características* }\end{array}$ & $\begin{array}{l}\text { Nenhuma ou } 1 \\
\text { e sem } \\
\text { características }\end{array}$ & $\begin{array}{l}\text { Mín } 2 \text { e com } 1 \\
\text { caractertica }\end{array}$ & $\begin{array}{c}\text { Mín } 2 \text { e com as } 3 \\
\text { características }\end{array}$ \\
\hline Dejetos & $\begin{array}{l}\text { Capacidade das } \\
\text { esterqueiras e } \\
\text { TRH }>120 \text { dias }\end{array}$ & $\begin{array}{c}\text { Capacidade e } \\
\text { TRH } \\
\text { insuficiente }\end{array}$ & $\begin{array}{c}\text { Capacidade } \\
\text { Suficiente e TRH } \\
\text { insuficiente }\end{array}$ & $\begin{array}{l}\text { Capacidade e } \\
\text { TRH suficientes }\end{array}$ \\
\hline Bem estar animal & $\begin{array}{l}\text { Linha de cocho e } \\
\text { animal } / \mathrm{m}^{2} \text { baia }\end{array}$ & $\begin{array}{c}\mathrm{LC}< \\
30 \mathrm{~cm} / \text { animal e } \\
+1 \text { animal } / \mathrm{m}^{2} \\
\text { baia }\end{array}$ & $\begin{array}{l}\mathrm{LC}>30 \mathrm{~cm} / \mathrm{animal} \\
\mathrm{e}+1 \text { animal } / \mathrm{m}^{2}\end{array}$ & $\begin{array}{c}\mathrm{LC}>30 \mathrm{~cm} / \mathrm{animal} \\
\text { e }-1 \text { animal } / \mathrm{m}^{2}\end{array}$ \\
\hline Água & $\begin{array}{l}\text { Fontes e estado de } \\
\text { conservação }\end{array}$ & $\begin{array}{l}1 \text { fonte não } \\
\text { preservada }\end{array}$ & $\begin{array}{l}2 \text { fontes não } \\
\text { preservadas }\end{array}$ & $\begin{array}{l}2 \text { ou }+ \text { fontes } \\
\text { preservadas }\end{array}$ \\
\hline $\begin{array}{l}\text { Limpeza das } \\
\text { Instalações }\end{array}$ & $\begin{array}{l}\text { Frequência de } \\
\text { limpeza e } \\
\text { desinfecção }\end{array}$ & $\begin{array}{c}-1 \text { X/dia e des. } \\
\text { a cada dois } \\
\text { lotes }\end{array}$ & $\begin{array}{l}\text { 1X/dia e des. a } \\
\text { cada dois lotes }\end{array}$ & $\begin{array}{c}1 \text { ou +/dia e des. } \\
\text { a cada lote }\end{array}$ \\
\hline $\begin{array}{l}\text { Descarte de } \\
\text { Resíduos sólidos }\end{array}$ & $\begin{array}{l}\text { Como descarta } \\
\text { (resíduos saúde, } \\
\text { embalagens) }\end{array}$ & $\begin{array}{l}\text { Enterra ou } \\
\text { queima }\end{array}$ & $\begin{array}{l}\text { Correto destino } \\
\text { parcial }\end{array}$ & $\begin{array}{c}\text { Correto destino } \\
\text { total }\end{array}$ \\
\hline $\begin{array}{l}\text { Vetores e } \\
\text { Roedores }\end{array}$ & Forma de controle & $\begin{array}{l}\text { Não há } \\
\text { controle }\end{array}$ & $\begin{array}{l}\text { Há controle } \\
\text { parcial }\end{array}$ & Há controle total \\
\hline $\begin{array}{l}\text { Manejo de Solo } \\
\text { (MS) }\end{array}$ & $\begin{array}{l}\text { Realiza algum } \\
\text { MS? } \\
\text { (PD,RC e } \\
\text { terraceamento) }\end{array}$ & $\begin{array}{l}\text { Não realiza PD } \\
\text { nem RC }\end{array}$ & PD e sem RC & $\begin{array}{c}\mathrm{PD}, \mathrm{RC} \text { e } \\
\text { terraceamento }\end{array}$ \\
\hline Análise de Solo & $\begin{array}{l}\text { Frequência que } \\
\text { realiza? Há } \\
\text { planejamento e } \\
\text { monitoramento } \\
\text { para adubação? }\end{array}$ & $\begin{array}{c}\text { Não faz e não } \\
\text { planeja ou } \\
\text { monitora a } \\
\text { adubação }\end{array}$ & $\begin{array}{c}\text { Realizam } \\
\text { análise, mas } \\
\text { aplicam sem } \\
\text { planejamento e } \\
\text { monitoramento }\end{array}$ & $\begin{array}{l}\text { Realizam análise } \\
\text { e aplicam com } \\
\text { planejamento e } \\
\text { monitoramento }\end{array}$ \\
\hline
\end{tabular}

Fonte: Elaborada pelos autores.

Legenda: LO - licença de operação; LC - Linha de cocho; PD - plantio direto; RC - rotação de culturas; TRH tempo de retenção hidráulica.

*características: impermeabilização, cobertura e isolamento. 
de Sustentabilidade Organizacional (OLIVEIRA, 2002), adaptada pelos autores. Para tanto, identificaram-se 10 indicadores, criando-se uma matriz de avaliação dos temas propostos com a valoração de indicadores podendo variar de 1 a 3, para cada item (Tabela 1).

Importante destacar que dentre os indicadores criados não foi possível esgotar os elementos relacionados a cada critério de sustentabilidade, elegendo-se, em função do acesso aos dados e facilidade de monitoramento destes pelos próprios produtores, características primordiais, mas não únicas, na busca de sistemas produtivos sustentáveis.

Realizou-se uma pesquisa tipo survey, aplicando-se um questionário semiestruturado (TRIVIÑOS, 1990; THIOLLENT, 1992; GIL, 2008), na forma de entrevista (TRIVIÑOS, 1990; SOUZA, 1993), a 31 suinocultores no município de Aratiba - RS. Determinou-se o tamanho da amostra de acordo com Oliveira (2006) e a seleção dos integrantes da amostra se deu por conveniência (THRUSFIELD, 2004), em função do acesso aos dados junto às três empresas integradoras que respondem pela quase totalidade dos sistemas de integração em terminação de suínos no município.

O questionário, construído para aplicação do Método de Avaliação de Indicadores de Sustentabilidade organizacional (M.A.I.S.) (OLIVEIRA, 2002), adaptado por Allegretti (2013) à suinocultura de terminação, era composto por questões abrangendo 10 critérios e analisadas com referência ao ano de 2011.

Neste método, cada critério avaliado (correspondendo às questões do questionário) recebe uma pontuação de acordo com o enquadramento da resposta (em desequilíbrio $=1$, em busca de equilíbrio $=2$ e em equilíbrio =3) sendo as médias atribuídas a cada critério, dentre as propriedades analisadas, demonstradas sob a forma de gráficos-radar.

Foram realizadas distribuições de frequência da população amostrada quanto aos critérios observados visando avaliar o número de propriedades relacionadas a cada índice.

A exigência estabelecida na Resolução 196/96 do Conselho Nacional de Saúde (BRASIL, 1996) de que toda pesquisa que envolva humanos se processe após consentimento livre e esclarecido dos sujeitos, indivíduos ou grupos foi atendida à medida que, ao responder o questionário, a pessoa concordou expressamente com a participação na pesquisa e divulgação dos resultados.

\section{Resultados e discussão}

Dentre os indicadores ambientais analisados, a busca do status "em equilíbrio" para as propriedades amostradas requer que a totalidade dos temas abordados situe-se no limite externo do gráfico radar apresentado abaixo. Porém, desperta atenção o desempenho crítico (status em desequilíbrio) verificado em alguns critérios (dejetos e descarte de embalagens), da mesma forma que o status em busca de equilíbrio (valor 2) permeia a maioria dos critérios avaliados.

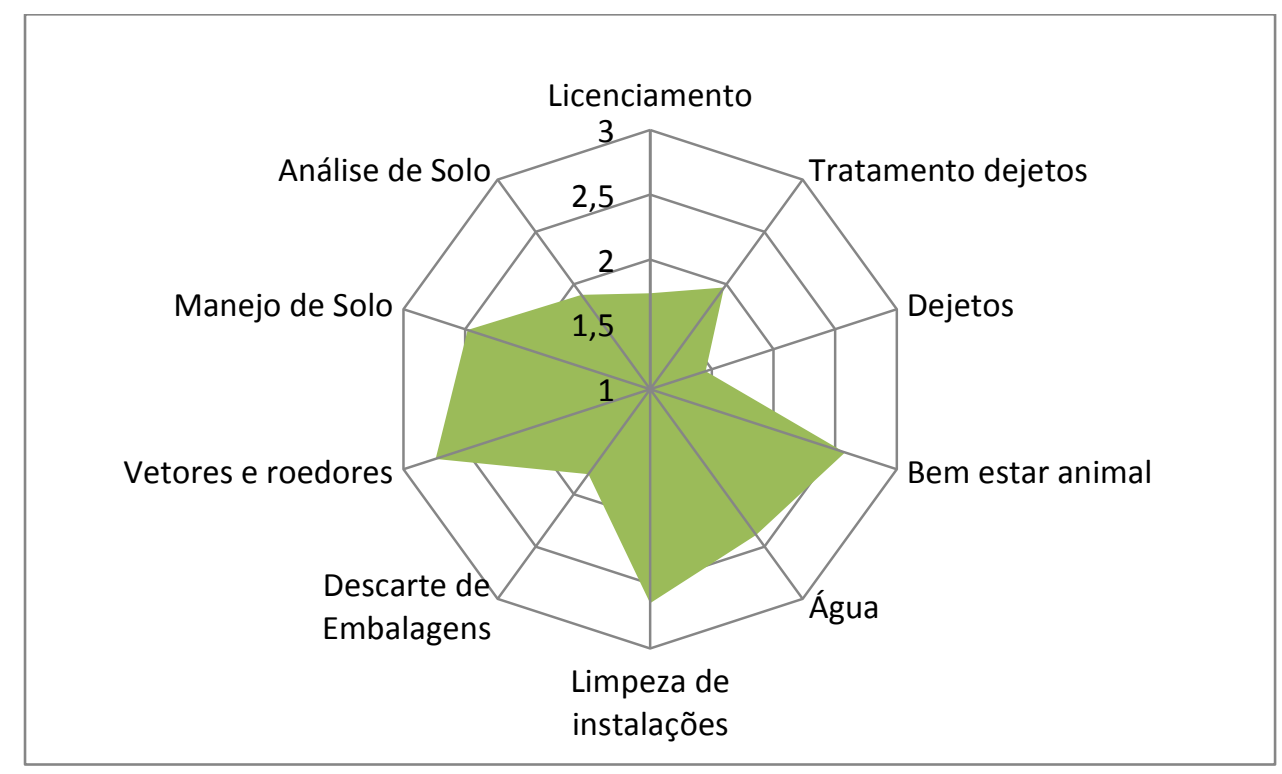

Figura 1:1Valores médios atribuídos aos indicadores de desempenho na dimensão ambiental a propriedades em sistemas integrados de produção de suínos de terminação, em Aratiba, RS, no ano de 2011.

Fonte: elaborada pelos autores 
O indicador mais crítico analisado diz respeito à produção de dejetos $(1,45)$. Para este indicador, confrontaram-se os dados de capacidade das esterqueiras (declarados pelos produtores) frente aos dados de produção de dejetos (calculado a partir do rebanho, acrescido de uma margem de segurança de $20 \%$ ) e o tempo de retenção hidráulica (TRH) médio declarado pelos produtores, apesar do TRH mínimo recomendado ser de 120 dias (FEPAM, 2007).

O incorreto dimensionamento das instalações destinadas ao tratamento de dejetos, o reduzido tempo de retenção hidráulica (TRH < 120 dias) para estabilização dos dejetos no caso de esterqueiras, associado ao desperdício de significativos volumes de água pelo ineficiente manejo das propriedades, conferiram uma limitação das propriedades amostradas no município quanto ao indicador de desempenho avaliado, determinando o desequilíbrio na classificação proposta, demonstrado pela atribuição de valor 1 à $64,52 \%$ das propriedades.

Já a análise do indicador descarte de resíduos sólidos $(1,81)$ remete a questões relacionadas à saúde pública e educação ambiental, mas também à necessidade de infraestrutura do município para coleta e correta destinação destes resíduos ou orientação quanto a esta destinação. O descarte de materiais de saúde (vidraria, seringas e agulhas) foi considerado um ponto crítico, uma vez que muitos produtores, por falta de informação ou desconhecimento, encaminham este material à coleta seletiva junto a vidros e plásticos ou, ainda, enterram ou queimam os resíduos na propriedade. A falta de um planejamento e orientação, por parte do poder público ou mesmo das indústrias integradoras, acaba comprometendo o desempenho deste indicador e contribuindo para o desequilíbrio ambiental da atividade e mesmo do ambiente rural como um todo.

A aplicação desregrada e sem planejamento dos dejetos no solo, mesmo após o correto TRH, compromete o equilíbrio ambiental das propriedades avaliadas. A partir do indicador análise de solo $(1,90)$ observou-se que a grande maioria das propriedades analisadas não executa periodicamente esta prática prévia à aplicação dos dejetos, conforme as exigências detectadas em cada amostra de solo. Seganfredo $(1999$, p. 16) já alertava:

[...] enquanto persistir o desequilíbrio entre a composição química dos dejetos e a quantidade de nutrientes requerida pelas plantas, recomenda-se um alerta quanto à sustentabilidade dos sistemas agrícolas adubados com tais detritos, porque resultarão em acúmulo de nutrientes no solo que, em excesso, serão nocivos ao ambiente.

Análises periódicas de solo associadas a um planejamento e monitoramento da aplicação dos dejetos são pontos fundamentais a serem abordados. A preocupação com a utilização de práticas de gestão e manejo voltadas a busca de um equilíbrio químico do solo, permite que a produtividade agrícola não fique comprometida gerando, consequentemente, receitas adicionais às propriedades rurais e ao município.

Verificou-se que o poder público municipal, no intuito de facilitar e auxiliar o manejo de destinação dos dejetos fornece equipamentos e mão de obra para a remoção periódica destes, quando contratado, destinando-os às demais propriedades agropecuárias do município para biofertilização de pastagens e lavouras. Constatou-se que por meio desta prática, o tempo de retenção hidráulica dos dejetos antes de serem retirados das propriedades, muitas vezes, acaba comprometido (TRH $<120$ dias), principalmente na época de preparo de solo pré-plantio, quando número expressivo de propriedades requer este fertilizante em função do baixo custo (somente o pagamento dos serviços de remoção dos dejetos à prefeitura), pressionando os suinocultores a entregá-los.

Este tipo de serviço prestado, apesar de permitir uma melhor distribuição dos dejetos pela área total do município, quando mal planejado (TRH incorreto, associado a não realização de análises de solo e dos dejetos prévias às aplicações e a um monitoramento das áreas aplicadas), torna o problema ambiental maior do que somente a abrangência das propriedades suinícolas, comprometendo o solo e os recursos hídricos podendo, no longo prazo, interferir na produtividade agrícola e no equilíbrio de outras dimensões da sustentabilidade no município, como a econômica e a social.

Apesar de a ferramenta desenvolvida buscar analisar sistemas produtivos de criação de suínos em terminação, alguns fatores ultrapassam o controle do suinocultor avaliado. A realidade verificada no município, e descrita no parágrafo acima, demonstra uma de suas limitações. Muitas vezes, apesar do produtor dispor de capacidade de armazenagem de dejetos (esterqueiras) suficiente para seu rebanho, fatores externos levam-no a reduzir o TRH utilizado, transferindo os riscos de desequilíbrio do solo para as demais propriedades do município.

Dentre os demais indicadores avaliados na dimensão ambiental, nenhum critério recebeu pontuação máxima. Entretanto, receberam destaque positivo os indicadores vetores e roedores $(2,74)$, limpeza das instalações $(2,65)$ e bem estar animal $(2,58)$. Todos estes indicadores possuem relação direta com as orientações técnicas fornecidas pelas agroindústrias ou cooperativas de integração, cabendo ao produtor adequá-los ao manejo da sua propriedade já que estes itens, na maioria das empresas, fazem parte do check list obrigatório, que contribui para a formação do preço e remuneração do suinocultor.

Cabe salientar que a avaliação proposta para estes critérios não compreende a integralidade dos elementos referentes a bem estar animal, limpeza das instalações ou vetores e roedores para classificarmos uma propriedade como sustentável, podendo futuramente serem incorporados novos elementos na análise no intuito de suprir tais limitações.

A distribuição de frequência de cada um dos indicadores ambientais avaliados (Figura 2) mostra que somente 


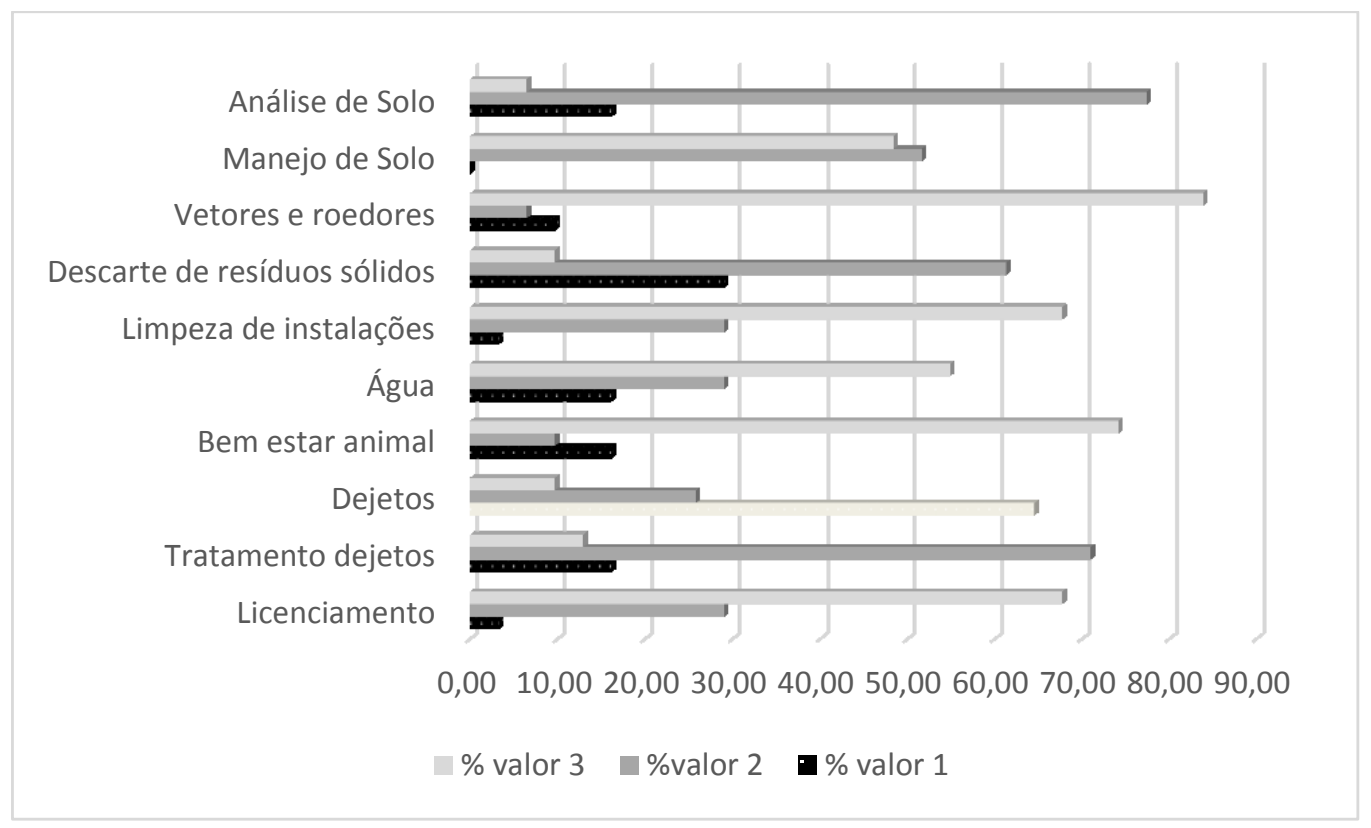

Figura 2: Distribuição de frequência dos valores atribuídos aos indicadores ambientais nas 31 propriedades do município de Aratiba, RS, no ano de 2011.

Fonte: elaborada pelos autores

os indicadores bem estar animal (74,19\%), limpeza das instalações $(67,74 \%)$, vetores e roedores $(83,87 \%)$, água $(54,84 \%)$ e licenciamento $(67,74 \%)$ receberam valor 3 (status em equilíbrio) em mais de $50 \%$ das propriedades. Já os indicadores tratamento de dejetos $(70,97 \%)$, descarte de resíduos sólidos $(61,29 \%)$ e manejo de solo $(51,61 \%)$ receberam valor 2 (status em busca de equilíbrio) em mais de $50 \%$ das propriedades. Como indicador crítico tanto em valor atribuído (1 - status em desequilíbrio) como em frequência de ocorrência (mais de $50 \%$ das propriedades avaliadas) aparece o item dejetos (64,52\%) demonstrando a importância da análise dos impactos deste fator ambiental na atividade no município.

Considerando que o status em desequilíbrio e em busca de equilíbrio requerem maiores atenções para a análise e proposição de soluções ou ações visando a correção e melhoria dos impactos ambientais destes itens no município, somou-se a distribuição de frequência destes dois níveis (valores 1 e 2) para confrontação ao status desejável (valor 3 - em equilíbrio) gerou-se um novo gráfico (Figura 3 ).

Observa-se que os indicadores tratamentos de dejetos $(87,10 \%)$, dejetos $(90,33 \%)$, descarte de resíduos sólidos $(90,32 \%)$, manejo de solo $(51,61 \%)$ e análise de solo $(93,55 \%)$ foram os indicadores que se apresentaram como críticos à grande maioria das propriedades analisadas, requerendo uma atenção especial do poder público ou mesmo dos proprietários e cooperativas quanto à correção destes itens na busca por um ambiente natural e desejável ao município.

A questão dos dejetos, que permeia mais de um dos indicadores ambientais críticos supracitados, requer um planejamento e orientação por parte do poder público, tendo em vista as questões de saúde pública e interesses econômicos do município quanto à produção e produtividade das áreas agrícolas. A contaminação e o desequilíbrio dos solos em função da falta de análises periódicas do solo e dos biofertilizantes a serem aplicados, aliado a uma falta de planejamento e monitoramento da adubação nas áreas agrícolas demonstra-se crítica em $93,55 \%$ das propriedades analisadas, podendo vir a comprometer o lençol freático e os recursos hídricos do município uma vez que algumas destas propriedades situam-se às margens de um significativo rio brasileiro, o Rio Uruguai. Soluções tecnológicas devem ser pensadas como a implantação de biodigestores a fim de solucionar questões ambientais comuns com eventual geração de renda extra a estes produtores, através da comercialização dos subprodutos desta tecnologia (biogás e biofertilizante).

Já os indicadores licenciamento $(67,74 \%)$, bem estar animal $(74,19 \%)$, água $(54,84 \%)$, vetores e roedores $(83,87 \%)$ e limpeza das instalações $(67,74 \%)$ apesar de demonstrarem o status em equilíbrio em mais de 50\% das propriedades avaliadas ainda requerem ações que permitam a busca pela adoção de novas práticas de gestão e manejo das propriedades suinícolas para viabilizar a busca pela sustentabilidade no município como um todo. Da mesma forma, a evolução da metodologia desenvolvida, incorporando critérios complementares a estes indicadores, permitirá melhorias e ganhos na avaliação de sustentabilidade. 
Questões como licenciamento ambiental requerem ajustes individuais de cada propriedade, o que foi percebido através dos depoimentos de alguns suinocultores que desenvolvem a atividade há muitos anos e que a legislação ambiental, apesar de existente, não era fiscalizada. Nestes casos, somente a realocação das instalações para áreas com o distanciamento mínimo dos recursos hídricos requerido pela legislação, permitiria a permanência deste suinocultor na atividade. Já questões de incorreto dimensionamento das instalações, principalmente da capacidade das esterqueiras, podem ser corrigidas através de investimentos privados das propriedades consideradas irregulares.

O indicador água refere-se à disponibilidade de fontes (meios de acesso) e preocupação na preservação destas nas propriedades avaliadas. As oscilações climáticas sentidas nos últimos anos na região, em função de secas prolongadas, têm levado muitos produtores a restringir seus investimentos na atividade pela falta de meios alternativos de acesso a este recurso primordial. Conscientização na preservação destes recursos naturais (fontes naturais), da mesma forma que maiores investimentos (públicos e privados) em meios alternativos, devem ser planejados para o crescimento e continuidade da atividade no município.

Práticas como a adoção de cisternas já observadas em algumas propriedades, inclusive com auxílio financeiro do poder público para sua instalação, são exemplos de soluções a serem pensadas e implementadas em maior escala.

\section{Conclusão}

A confrontação dos resultados encontrados a partir da classificação proposta por esta metodologia de avaliação de indicadores de desempenho ambiental voltados a sustentabilidade, e a realidade verificada nas propriedades demonstrou algumas limitações da metodologia que dificultam a generalização dos resultados. Porém, a análise individualizada destes indicadores permitiu o alerta de muitos pontos críticos a serem observados na busca de um equilíbrio ambiental da atividade no município.

Ações de planejamento públicas ou privadas do setor poderão ser tomadas a partir deste reconhecimento, viabilizando assim a continuidade desta atividade representativa para o desenvolvimento regional, da mesma forma que inúmeros impactos ambientais podem ser mitigados em benefício da população como um todo.

O monitoramento destes indicadores no decorrer dos anos, associado à incorporação de novos critérios complementares a cada indicador, como sugerido na pesquisa, permitirão uma avaliação evolutiva voltada à sustentabilidade nas propriedades suinícolas de terminação. A busca da sustentabilidade ambiental da atividade neste ou em qualquer outro município que tenha na suinocultura uma de suas bases econômicas e sociais é fundamental para garantia do desenvolvimento regional e manutenção da qualidade de vida.

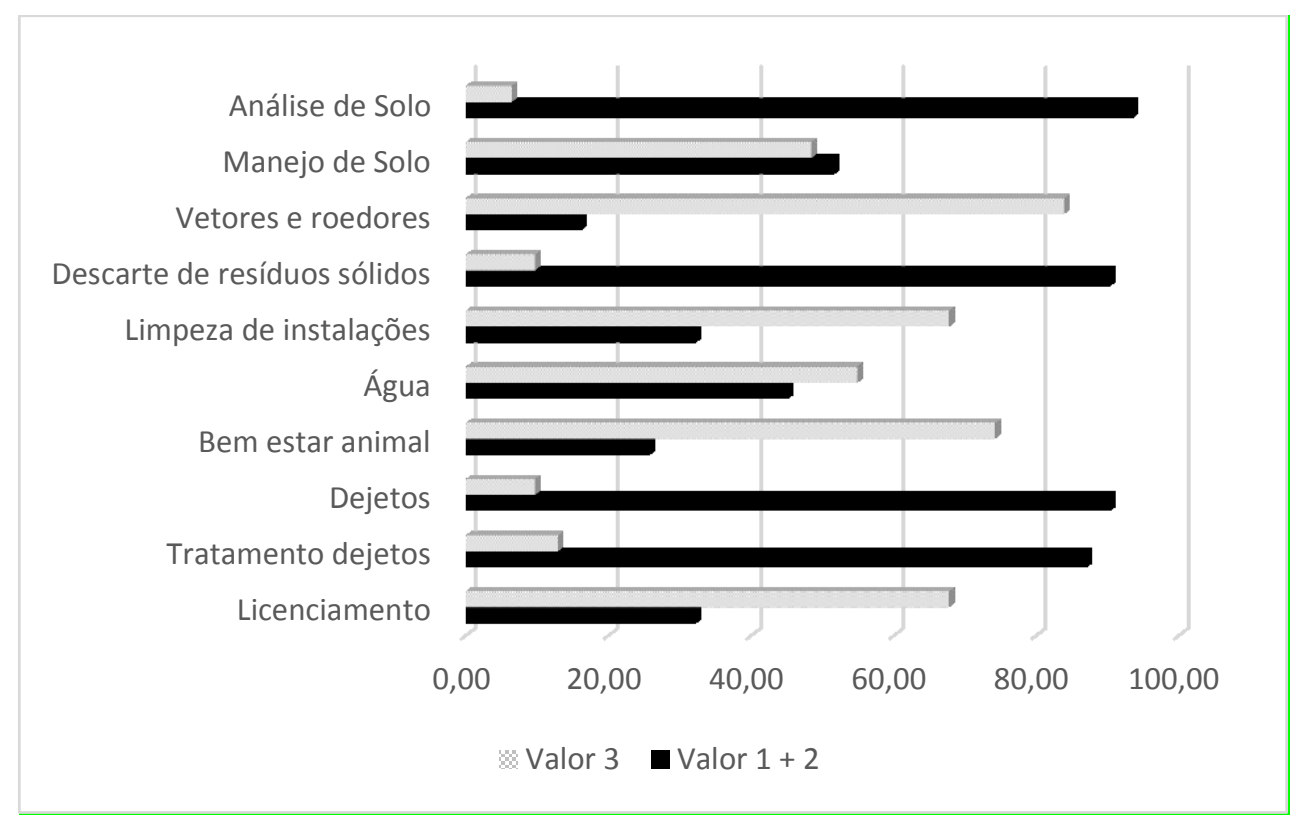

Figura 3: Distribuição de frequência do status em equilíbrio (valor 3) e em busca de equilíbrio + em desequilíbrio (valor $1+2$ ) nas 31 propriedades do município de Aratiba, RS, no ano de 2011.

Fonte: elaborada pelos autores. 


\section{Agradecimentos}

À CAPES, instituição financiadora desta pesquisa, e aos suinocultores de terminação, empresas (corpo técnico e administrativo) e poder público municipal de Aratiba que colaboraram para a construção e desenvolvimento da presente pesquisa.

\section{Referências}

ALLEGRETTI, G. Integração das dimensões social, ambiental e econômica na terminação de suínos: construção de indicadores de desempenho e validação em um município do Rio Grande do Sul. 2013. 146 f. Dissertação (Mestrado) Programa de Pós-Graduação em Agronegócios, Centro de Estudos e Pesquisas em Agronegócios, Universidade Federal do Rio Grande do Sul, Porto Alegre, 2013.

BRASIL. Conselho Nacional de Saúde. Resolução no 196/96. Estabelece as diretrizes e normas regulamentadoras de pesquisas envolvendo seres humanos. Disponível em: <http://www.ufrgs.br/ bioetica/res19696.htm>. Acesso em: 16 mar. 2010.

CLARO, P. B. de O.; CLARO, D. P. Desenvolvimento de indicadores para monitoramento de sustentabilidade: o caso do café orgânico. Revista de Administração, São Paulo, v. 39, n. 1, p. 18-29, jan./mar. 2004.

\section{FEPAM - FUNDAÇÃO ESTADUAL DE PROTEÇÃO} AMBIENTAL HENRIQUE LUIZ ROESSLER. Critérios técnicos para o licenciamento ambiental de novos empreendimentos destinados à suinocultura. Porto Alegre, 2007. Disponível em: $<$ http://www.fepam.rs.gov.br/central/diretrizes/ diret_suinos_novos.pdf $>$. Acesso em: 20 jun. 2011.

GIL, A. C. Métodos e técnicas de pesquisa social. 6. ed. São Paulo: Atlas, 2008.

IBGE - INSTITUTO BRASILEIRO DE GEOGRAFIA E ESTATÍSTICA. Brasília: Diretoria de Pesquisas, Coordenação de Agropecuária, Pesquisa da Pecuária Municipal, 2011.

MIELE, M. Contratos, especialização, escala de produção e potencial poluidor na suinocultura de Santa Catarina. 2006. 286 f. Tese (Doutorado) - Programa de Pós-Graduação em Agronegócios, Centro de Estudos e Pesquisas em Agronegócios, Universidade Federal do Rio Grande do Sul, Porto Alegre, 2006.
MIELE, M. et al. Custos de produção de suínos em países selecionados, 2010. Concórdia, SC: EMBRAPA-CNPSA, 2011. (Comunicado Técnico 499).

OLIVEIRA, A. G. de. Bioestatística, epidemiologia e investigação. Lisboa: LIDEL, 2006.

OLIVEIRA, J. H. R. de. M.A.I.S.: Método para Avaliação de Indicadores de Sustentabilidade Organizacional. 2002. 217 f. Tese (Doutorado) Programa de Pós-Graduação em Engenharia de Produção, Universidade Federal de Santa Catarina, Florianópolis, 2002.

RODIGHERI, J. A. Carnes: situação da suinocultura brasileira e catarinense. 2011. Disponível em $<$ http://cepa.epagri.sc.gov.br/Informativos_ agropecuarios/Carnes/carnes_suina_27.06.2011. htm>. Acesso em: 11 set. 2012.

SANTOS FILHO, I. J. et al. Consolidação do custo do suinocultor para a produção de suínos em sistema de parceira em Santa Catarina: ano 2011. Concórdia: EMBRAPA Suínos e Aves, 2011. (Comunicado Técnico, n. 497).

SEAPA. SAN - Secretaria da Agricultura, Pecuária e Abastecimento. Sistema de Análise de Negócios. [2011]. Disponível em: <https://san.procergs. rs.gov.br/apl/san/SAN-PVTAB-CON_Default. asp?dt=135531097 2984>. Acesso em: 12 dez. 2012.

SEGANFREDO, M. A. Os dejetos de suínos são um fertilizante ou poluente do solo? Caderno de Ciência \& Tecnologia, Brasília, v. 16, n. 3, p. 129141, 1999.

SOUZA, M. L. Desenvolvimento de Comunidade e participação. 4. ed. São Paulo: Cortez, 1993.

THIOLLENT, M. Metodologia da pesquisa-ação. 5. ed. São Paulo: Cortez, 1992.

THRUSFIELD, M. Epidemiologia veterinária. 2. ed. São Paulo: Roca, 2004.

TRIVIÑOS, A. S. N. Introdução à pesquisa participante em ciências sociais: a pesquisa qualitativa em educação. São Paulo: Cortez, 1990. 